В. Н. Гонин, Ж. Б. Тумунбаярова, М. Д. Анщиферова. Методический подход к оценке неформальной занятости населения в России

Научная статья

УДК 331.5

DOI: $10.18101 / 2304-4446-2021-2-11-18$

\title{
МЕТОДИЧЕСКИЙ ПОДХОД К ОЦЕНКЕ НЕФОРМАЛЬНОЙ ЗАНЯТОСТИ НАСЕЛЕНИЯ В РОССИИ
}

( ) Гонин Валерий Николаевич

кандидат экономических наук, профессор

vngonin@mail.ru

(C) Тумунбаярова Жаргал Баировна

кандидат экономических наук, доцент tzhargal@list.ru

(C) Анциферова Мария Дмитриевна

обучающийся

antsiferova_mari@mail.ru

Забайкальский государственный университет

Россия, 672039, г. Чита, ул. Александро-Заводская, д. 30

Аннотация. В статье дается краткий анализ уровня неформальной занятости в России. Представлен методический подход к оценке неформальной занятости населения, основанной на данных налоговых органов, а также сводных показателях статистики, с использованием косвенных индикаторов теневой экономики. Предложенная методика позволила провести оценку налоговых потерь от неформальной занятости населения в России, Забайкальском крае. Проведенное исследование подтверждает тот факт, что вопрос поиска методик оценки масштабов неформальной занятости является актуальным по причине снижения потенциала доходообразования бюджетов различных уровней (наличие потерь по НДФЛ негативно отражается на бюджетах регионального и местного уровня), а также отсутствия социальных гарантий при неформальной занятости. Поэтому государство заинтересовано в поиске лучших методик по оценке масштабов неформальной занятости и мер по противодействию этой практике.

Ключевые слова: неформальная занятость, теневая экономика, налоговые потери, НДФЛ, Забайкальский край, трудовые ресурсы

\section{Для цитирования}

Гонин В. Н., Тумунбаярова Ж. Б., Анциферова М. Д. Методический подход к оценке неформальной занятости населения в России // Вестник Бурятского государственного университета. Экономика и менеджмент. 2021. № 2. С. 11-18.

Неформальная занятость как предмет изучения модифицируется в своем развитии, однако при этом одновременно усложняется. Актуальность данного исследования обусловлена масштабностью распространения данного явления, вызывая интерес с точки зрения многофункциональности, она не подвластна учету и контролю, оказывая значительное влияние на социальную напряженность, но при этом способствует увеличению занятости как особый социальный стабилизатор в обществе. 
Оценить масштабы распространения неформальной занятости и подтвердить документально - непростая задача. Согласно мнению Г. Гроссмана, «измерение неизмеримого остается проблемой» [1], тем не менее необходимо проводить оценку масштабов распространения данного явления.

По данным органов государственной статистики, наибольшее число неформально занятых граждан по видам экономической деятельности преобладает в оптовой, розничной торговле $(33,8 \%)$, на втором месте сельское хозяйство $(15,5 \%)$, а третье место строительство $(11,4 \%)$ (рис. 1$)$.
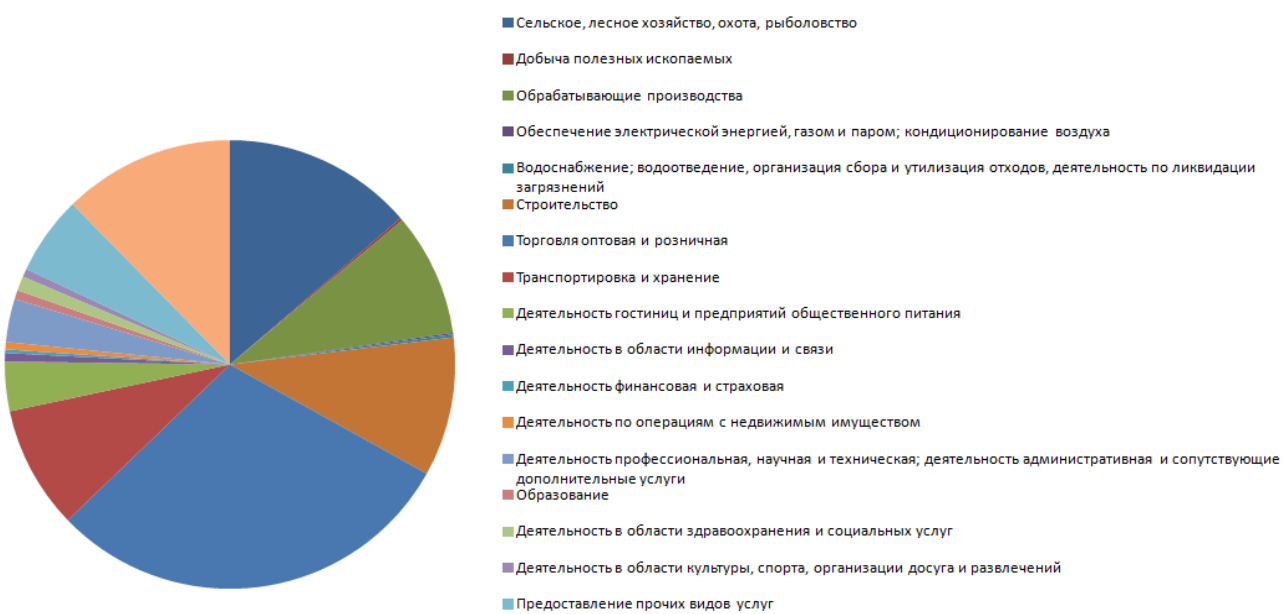

Рис. 1. Удельные веса занятых в неформальном секторе по видам экономической деятельности за 2018 год в Российской Федерации ${ }^{1}$

Такая статистика подтверждает высокую потребность в рабочей силе в данных отраслях. На такие отрасли, как добыча полезных ископаемых, образование, средства массовой информации, культура и спорт, приходится не более $1 \%$ неформально занятого населения (рис. 1).

Дополнительно к представленной статистике можно использовать метод расчета по показателю занятости, который предполагает сопоставление данных о рабочих местах [2]. За анализируемый период общее количество занятых в Российской Федерации увеличилось на 815,4 тыс. человек.

С 2015 по 2018 г. наблюдается сокращение числа занятых в организациях. Наличие разрыва между двумя этими показателями свидетельствует о наличии неформальной занятости в экономике (рис. 2).

В дополнение к существующим методам оценки масштабов неформальной занятости авторами предлагается использовать метод альтернативных расчетов,

\footnotetext{
${ }^{1}$ Труд и занятость в России 2019 год / Федеральная служба государственной статистики. URL: https://www.gks.ru/storage/mediabank/Trud_2019.pdf — Загл. с экрана (дата обращения: 10.03.2021). Текст: электронный.
} 
В. Н. Гонин, Ж. Б. Тумунбаярова, М. Д. Анџиферова. Методический подход к оценке неформальной занятости населения в России

который учитывает различия в методиках оценки рынка труда посредством сравнения таких индикаторов, как количество занятых в экономике в целом с данными о количестве налогоплательщиков налога на доходы физических лиц (далее НДФЛ). На основе зафиксированных расхождений определяются масштабы неформальной занятости.

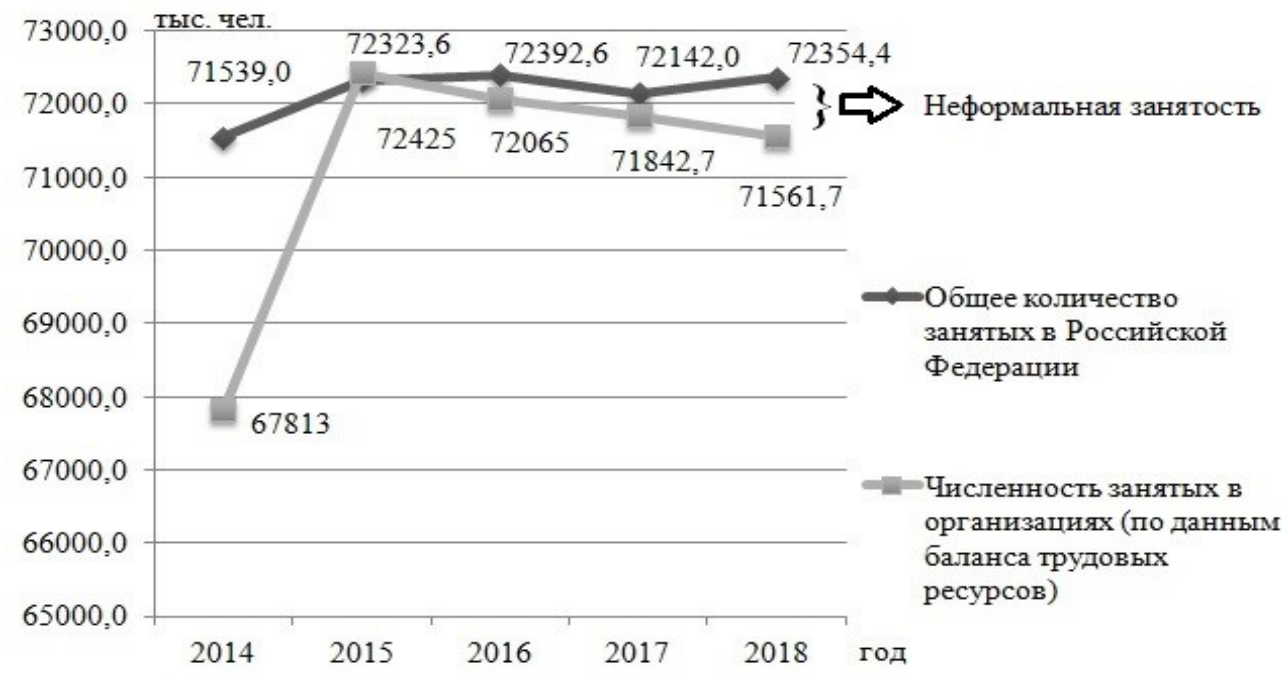

Рис. 2. Динамика занятости в Российской Федерации за 2014-2018 гг.

Основным источником информации о количестве занятых в экономике являются данные органов государственной статистики [3]. В качестве базы данных исследования была использована статистическая оценка численности занятых в экономике, рассчитанная службой государственной статистики в соответствии с методологией расчета баланса трудовых ресурсов. Согласно этим данным, за анализируемый период количество занятых в экономике увеличилось на 0,8 млн человек (табл. 2).

Таблица 2

Анализ трудовых ресурсов в Российской Федерации за 2014-2018 гг. ${ }^{1}$, млн чел.

\begin{tabular}{|l|c|c|c|c|c|}
\hline \multicolumn{1}{|c|}{ Показатель } & 2014 & 2015 & 2016 & 2017 & 2018 \\
\hline $\begin{array}{l}\text { Общее количество занятых в экономике } \\
\text { (по данным Росстата) }\end{array}$ & 71,5 & 72,3 & 72,3 & 72,1 & 72,3 \\
\hline $\begin{array}{l}\text { Количество налогоплательщиков НДФЛ } \\
\text { (по данным ФНС) }\end{array}$ & - & 59,9 & 58,3 & 57,2 & 56,8 \\
\hline
\end{tabular}

\footnotetext{
${ }^{1}$ Отчет о налоговой базе и структуре начислений по налогу на доходы физических лиц, удерживаемому налоговыми агентами // составил и разработал орган Федеральной налоговой службы. URL: https://www.nalog.ru/rn75/related_activities/statistics_and_analytics/ forms/ - Загл. с экрана (дата обращения: 10.03.2021). Текст: электронный; Численность занятых по субъектам Российской Федерации [Электронный ресурс] // Федеральная служба государственной статистики. URL: https:/www.gks.ru/free_doc/ new_site/population/trud/tab_trud2.htm — Загл. с экрана (дата обращения: 10.03.2021). Текст: электронный.
} 
В качестве исходной информационной базы для оценки количества налогоплательщиков были использованы данные налоговых органов о заработной плате, с которой был уплачен налог на доходы физических лиц.

Для расчётов был взят отчет по форме № 5-НДФЛ - отчет о налоговой базе и структуре начислений по налогу на доходы физических лиц, удерживаемому налоговыми агентами, который ФНС Российской Федерации выкладывает по всем регионам России. Раздел 1 данного отчета содержит информацию о «количестве сведений о доходах физических лиц» и «количестве физических лиц, получивших доходы». Для определения количества налогоплательщиков, с заработной платы которых был уплачен налог на доходы физически лиц, была использована информация по коду 2000, основной код для заработной платы. Под кодом 2000 понимается вознаграждение, которое получает налогоплательщик за выполнение трудовых или иных обязанностей, то есть заработная плата в рамках трудовых отношений. Количество налогоплательщиков по НДФЛ содержится в столбе 2 «количество физических лиц, получивших доход» по коду дохода 2000. Для исследования был проведен анализ за 2015-2018 гг., потому что в отчетах № 5-НДФЛ до 2015 года отсутствует столбец, характеризующий «количество физических лиц, получивших доход».

Таблица 3

Количество неформально занятых граждан в структуре рабочей силы на территории России за 2014-2018 гг. ${ }^{1,2,3}$

\begin{tabular}{|c|c|c|c|c|c|}
\hline Показатель & 2014 & 2015 & 2016 & 2017 & 2018 \\
\hline \multicolumn{6}{|c|}{ Количество, млн чел. } \\
\hline Численность рабочей силы & 75,4 & 76,5 & 76,6 & 76,1 & 76,0 \\
\hline $\begin{array}{l}\text { Численность неформально заня- } \\
\text { тых, выпадающих из поля зрения } \\
\text { налоговой статистики }\end{array}$ & - & 12,4 & 14,0 & 14,9 & 15,5 \\
\hline \multicolumn{6}{|c|}{ Удельный вес, в \% } \\
\hline Численность рабочей силы & 100 & 100 & 100 & 100 & 100 \\
\hline $\begin{array}{l}\text { Численность неформально заня- } \\
\text { тых, выпадающих из поля зрения } \\
\text { налоговой статистики }\end{array}$ & - & 16,21 & 18,28 & 19,58 & 20,39 \\
\hline
\end{tabular}

\footnotetext{
${ }^{1}$ Труд и занятость в России 2019 год // Федеральная служба государственной статистики. URL: https://www.gks.ru/storage/mediabank/Trud_2019.pdf — Загл. с экрана (дата обращения: 10.03.2021). Текст: электронный.

2 Численность занятых по субъектам Российской Федерации / Федеральная служба государственной статистики. URL: https:/www.gks.ru/free_doc/new_site/population/trud/ tab_trud2.htm - Загл. с экрана (дата обращения: 10.03.2021). Текст: электронный.

3 Забайкальский края в цифрах // составил и разработал Территориальный орган Федеральной службы государственной статистики по Забайкальскому краю. URL: https://chita.gks.ru/storage/mediabank/10_5_2017.pdf — Загл. с экрана (дата обращения: 10.03.2021). Текст: электронный; Отчеты по налогу на доходы физических лиц по Забайкальскому краю // составил и разработал орган Федеральной налоговой службы. URL: https://www.nalog.ru/rn75/related_activities/statistics_and_analytics/forms/ - Загл. с экрана (дата обращения: 10.03.2021). Текст: электронный.
} 
В. Н. Гонин, Ж. Б. Тумунбаярова, М. Д. Анџиферова. Методический подход к оценке неформальной занятости населения в России

По оценке ФНС, в 2018 г. количество налогоплательщиков НДФЛ в Российской Федерации составило 56,8 млн человек. В то же время Росстат оценивает количество занятых в экономике (то есть работающих) россиян в 72,3 млн человек. Таким образом, количество неформально занятых граждан, выпадающих из поля зрения налоговой статистики, в 2018 г. составило 15,5 млн человек $(20,3 \%$ общей численности рабочей силы) (табл. 3).

По методике, основанной на сравнении таких индикаторов, как количество занятых в экономике в целом, с данными о количестве налогоплательщиков налога на доходы физических лиц, был осуществлен анализ неформальной занятости в Забайкальском крае.

Таблица 4

Анализ трудовых ресурсов в Забайкальском края за 2014-2018 гг. ${ }^{1}$

\begin{tabular}{|l|c|c|c|c|c|}
\hline \multicolumn{1}{|c|}{ Показатель } & 2014 & 2015 & 2016 & 2017 & 2018 \\
\hline $\begin{array}{l}\text { Общее количество занятых в экономике } \\
\text { (по данным Росстата) }\end{array}$ & 482 & 480 & 477,5 & 477,4 & 477,5 \\
\hline $\begin{array}{l}\text { Количество налогоплательщиков НДФЛ } \\
\text { (по данным ФНС) }\end{array}$ & - & 414,6 & 404,4 & 379,3 & 370,7 \\
\hline
\end{tabular}

По оценке ФНС, в 2018 г. количество налогоплательщиков НДФЛ в Забайкальском крае составило 370,7 тыс. человек. В то же время Росстат оценивает количество занятых в экономике (то есть работающих) россиян в 477,5 тыс. человек. Таким образом, количество неформально занятых граждан, выпадающих из поля зрения налоговой статистики, в 2018 г. составило 106,8 тыс. человек (20,08\% от общей численности рабочей силы) (табл. 5).

Таблица 5

Количество неформально занятых граждан в структуре рабочей силы на территории Забайкальского края за 2014-2018 гг. ${ }^{2}$, тыс. чел.

\begin{tabular}{|c|c|c|c|c|c|}
\hline Показатель & 2014 & 2015 & 2016 & 2017 & 2018 \\
\hline \multicolumn{6}{|c|}{ Количество, тыс. чел. } \\
\hline Численность рабочей силы & 535,2 & 535,7 & 535,1 & 534,8 & 532 \\
\hline $\begin{array}{l}\text { Численность неформально занятых (выпада- } \\
\text { ющие из поля зрения налоговой статистики) }\end{array}$ & - & 65,4 & 73,1 & 98,1 & 106,8 \\
\hline \multicolumn{6}{|c|}{ Удельный вес, в \% } \\
\hline Численность рабочей силы & 100 & 100 & 100 & 100 & 100 \\
\hline $\begin{array}{l}\text { Численность неформально занятых (выпада- } \\
\text { ющие из поля зрения налоговой статистики) }\end{array}$ & - & 12,21 & 13,66 & 18,34 & 20,08 \\
\hline
\end{tabular}

\footnotetext{
1 Забайкальский края в цифрах / составил и разработал Территориальный орган Федеральной службы государственной статистики по Забайкальскому краю. URL: https://chita.gks.ru/storage/mediabank/10_5_2017.pdf — Загл. с экрана (дата обращения: 10.03.2021). Текст: электронный; Отчеты по налогу на доходы физических лиц по Забайкальскому краю // составил и разработал орган Федеральной налоговой службы. URL: https://www.nalog.ru/rn75/related_activities/statistics_and_analytics/forms/ — Загл. с экрана (дата обращения: 10.03.2021). Текст: электронный.

${ }^{2}$ Там же.
} 
В соответствии с приведенной динамикой численности неформально занятых граждан, при помощи метода альтернативных расчетов, учитывающего различие в методиках оценки рынка труда, были рассчитаны налоговые потери от неформальной занятости населения в Российской Федерации.

Основываюсь на предположении, что неформально занятый гражданин получает минимальный размер оплаты труда, налоговые потери НДФЛ были рассчитаны по следующей формуле:

Потери НДФЛ, $=$ MPOT $_{\mathrm{n}} \mathrm{Ч}_{\mathrm{H} 3} \mathrm{x}$ i x N,

где МРОТ - минимальный размер оплаты труда (руб.);

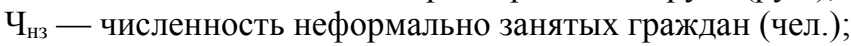

$i$ - налоговая ставка НДФЛ (\%);

$N$ - количество месяцев действия установленной суммы МРОТ;

$n$ - порядковый номер рассчитываемого года.

Таблица 6

Налоговые потери от неформальной занятости на территории

Российской Федерации за 2015-2018 гг. ${ }^{1}$

\begin{tabular}{|l|c|c|c|c|c|c|c|}
\hline \multicolumn{1}{|c|}{ Показатель } & 2015 & \multicolumn{2}{c|}{2016} & \multicolumn{2}{c|}{2017} & \multicolumn{2}{c|}{2018} \\
\hline МРОТ (руб.) & 5965 & 6204 & 7500 & 7500 & 7800 & 9489 & 11163 \\
\hline $\mathrm{N}$ (мес.) & 12 & 6 & 6 & 6 & 6 & 4 & 8 \\
\hline Чнз (млн чел.) & 12,4 & \multicolumn{2}{|c|}{14,0} & \multicolumn{2}{c|}{14,9} & 15,5 \\
\hline$i$ (\%) & 13 & \multicolumn{2}{|c|}{13} & \multicolumn{2}{|c|}{13} & \multicolumn{2}{c|}{13} \\
\hline Потери НДФЛ за год (млрд руб.) & 115,3 & \multicolumn{2}{|c|}{149,6} & \multicolumn{2}{|c|}{177,8} & 256,4 \\
\hline
\end{tabular}

Исследование показало, что потери НДФЛ вследствие большого числа неформально занятых граждан являются весьма значительными, за 2018 год налоговые потери составили 256,4 млрд рублей.

Налоговые потери в Забайкальском крае были рассчитаны с учетом районного коэффициента по следующей формуле:

Потери НДФЛ ${ }_{\mathrm{n}}=\left(\mathrm{MPOT}_{\mathrm{n}}+\left(\mathrm{MPOT}_{\mathrm{n}} \mathrm{x} \mathrm{K}\right)\right)$ x $\mathrm{Ч}_{\mathrm{H} 3} \mathrm{x}$ i x N, где МРОТ - минимальный размер оплаты труда (руб.);

$K$ - районный коэффициент (\%);

$\mathrm{Ч}_{\text {нз }}$ - численность неформально занятых граждан (чел.);

$i$ - налоговая ставка НДФЛ (\%);

$N$ - количество месяцев действия установленной суммы МРОТ;

$n$ - порядковый номер рассчитываемого года.

\footnotetext{
${ }^{1}$ Минимальный размер оплаты труда в Российской Федерации // Правовая справочноинформационная система «Консультант Плюс». URL: http://www.consultant.ru/ document/cons_doc_LAW_15189/ — Загл. с экрана (дата обращения: 10.03.2021). Текст: электронный.
} 
В. Н. Гонин, Ж. Б. Тумунбаярова, М. Д. Анциферова. Методический подход к оценке неформальной занятости населения в России

Таблица 7

Налоговые потери от неформальной занятости на территории Забайкальского края за 2015-2018 гг. ${ }^{1}$ [7]

\begin{tabular}{|c|c|c|c|c|c|c|c|}
\hline Показатель & 2015 & \multicolumn{2}{|c|}{2016} & \multicolumn{2}{|c|}{2017} & \multicolumn{2}{|c|}{2018} \\
\hline МРОТ (руб.) & 5965 & 6204 & 7500 & 7500 & 7800 & 9489 & 11163 \\
\hline $\mathrm{K}(\%)$ & 20 & \multicolumn{2}{|c|}{20} & \multicolumn{2}{|c|}{20} & \multicolumn{2}{|c|}{20} \\
\hline MPOT + K & 7158 & 7444,8 & 9000 & 9000 & 9360 & 11386,8 & 13395,6 \\
\hline $\mathrm{N}$ (мec.) & 12 & 6 & 6 & 6 & 6 & 4 & 8 \\
\hline Чнз (тыс. чел.) & 65,4 & \multicolumn{2}{|c|}{73,1} & \multicolumn{2}{|c|}{98,1} & \multicolumn{2}{|c|}{106,8} \\
\hline$i(\%)$ & 13 & \multicolumn{2}{|c|}{13} & \multicolumn{2}{|c|}{13} & \multicolumn{2}{|c|}{13} \\
\hline $\begin{array}{l}\text { Потери НДФЛ за } \\
\text { год (млн руб.) }\end{array}$ & 730,2 & \multicolumn{2}{|c|}{937,6} & \multicolumn{2}{|c|}{1404,8} & \multicolumn{2}{|c|}{2120,2} \\
\hline
\end{tabular}

Налоговые потери в Забайкальском крае за 2018 г. составили 2,1 млрд рублей. За анализируемый период потери от теневой занятости увеличились в 2018 г. по сравнению с 2015 г. на 1,3 млрд рублей.

Методика оценки масштабов неформальной занятости, основанная на разрыве в оценке труда, держится на предположении, что фиксируется лишь минимальная граница неформальной занятости, так как учитывается лишь та часть, которая выпадает из поля зрения налоговой статистики.

Таким образом, неформальная занятость обладает потенциалом для создания рабочих мест в условиях высокой безработицы из-за относительной легкости доступа, низких требований к сотрудникам: отсутствие образования и навыков. Однако при этом неформальная занятость создает рабочие места, не отвечающие критериям труда, что характеризуется отсутствием социальной защиты.

\section{Литература}

1. Костин А. В. Опыт измерения теневой экономики в западной литературе // Вестник НГУ. Серия: Социально-экономические науки. 2011. № 4. С. 33-43. Текст: непосредственный.

2. Цыренов Д. Д. Институт образования и рынок труда: качественное и количественное взаимодействие // Вестник Бурятского государственного университета. Экономика и менеджмент, 2014. № 1. С. 42-54. Текст: непосредственный.

3. Цыренов Д. Д. Оценка качества профессионального образования с учетом критерия занятости: теория и практика // Проблемы современной экономики. 2011. № 3. С. 315-318. Текст: непосредственный.

Статья поступила в редакцию 26.04.2021; одобрена после рецензирования 28.04.2021; принята к публикаичии 28.04.2021.

\footnotetext{
${ }^{1}$ Размер минимальной заработной платы в субъектах Российской Федерации // Правовая справочно-информационная система «Консультант Плюс». URL: http://www.consultant.ru/document/cons_doc_LAW_291114/ — Загл. с экрана (дата обращения: 10.03.2021). Текст: электронный.
} 


\section{METHODOLOGICAL APPROACH TO ASSESSMENT OF INFORMAL EMPLOYMENT IN RUSSIA}

Valery N. Gonin

Cand. Sci. (Econ.), Prof.

vngonin@mail.ru

Zhargal B. Tumunbayarova

Cand. Sci. (Econ.), A/Prof.

tzhargal@list.ru

Mariya D. Antsiferova

Student

antsiferova_mari@mail.ru

Transbaikal State University

30 Aleksandro-Zavodskaya St., Chita 672039, Russia

Abstract. The article provides a brief analysis of the level of informal employment in Russia. We present a methodological approach to assessing informal employment of the population based on the data from tax authorities, statistical consolidated indicators, and indirect indicators of the off-the-books economy. The proposed methods made it possible to assess tax losses from informal employment in Russia and Zabaykalsky Krai. The study confirms that finding the methods for assessing the scale of informal employment is relevant due to a decrease in the income producing potential of budgets of various levels (personal income tax losses negatively affects the budgets of the regional and local levels), and the lack of social guarantees for informal employment. Therefore, the state is interested in finding the best methods for assessing the scale of informal employment and measures to counter it.

Keywords: informal employment, the off-the-books economy, tax losses, personal income tax, Zabaykalsky Krai, labour resources

\section{For citation}

Gonin V. N., Tumunbayarova Zh. B., Antsiferova M. D. Methodological Approach to Assessment of Informal Employment in Russia. Bulletin of Buryat State University. Economy and Management. 2021; 2: 11-18 (In Russ.).

The article was submitted 26.04.2021; approved after reviewing 28.04.2021; accepted for publication 28.04.2021. 